\title{
Langetermijnresultaten van continent katheteriseerbare urostoma's bij volwassenen met niet-neurogene of neurogene blaasontledigingsstoornissen
}

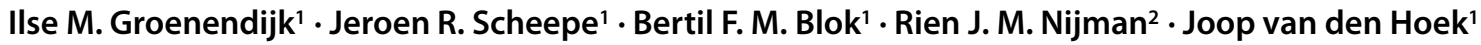

Published online: 5 August 2019

(c) The Author(s) 2019

\section{Samenvatting}

Het doel van deze studie was de langetermijnresultaten te beschrijven van continent katheteriseerbare urostoma's bij volwassenen voor neurogene en niet-neurogene indicaties. Er is een retrospectief onderzoek verricht naar de indicaties en complicaties van 41 patiënten die een continent urostoma aangelegd kregen in het Erasmus MC of het Universitair Medisch Centrum Groningen (UMCG) (van wie 29 vrouwen, gem. leeftijd 32 jaar, follow-up 52 mnd., $48 \% \geq 1$ re-operatie). Patiënten die ten tijde van dit onderzoek het stoma nog in gebruik hadden $(n=32)$, ontvingen een vragenlijst over tevredenheid, continentie en katheterisatie. Deze werd ingevuld door 24 patiënten; zij meldden gemiddeld 'veel verbetering' in hun situatie. Het aanleggen van een continent katheteriseerbaar urostoma bij volwassenen gaat gepaard met een hoge kans op re-operatie. Toch rapporteert de meerderheid van de patiënten met een urostoma dat hun situatie verbeterd is.

Trefwoorden continent katheteriseerbaar urostoma $\cdot$ volwassenen $\cdot$ re-operaties $\cdot$ complicaties

\section{Long-term results of continente catheterizable urinary channels in adults with non-neurogenic or neurogenic lower urinary tract dysfunction}

\begin{abstract}
The objective was to evaluate the long-term results after the construction of a continent catheterizable urinary conduit in adults. We retrospectively reviewed the charts of 41 adults who received a continent catheterizable urinary conduit and extracted indications and complications (29/41 women, average age 32, median follow-up durations 52 months, 48\% $\geq 1$ reoperation). Patients who were still using the conduit during this research $(n=32)$ were sent a questionnaire about their impression of improvement, continence and catheterization problems. 24 patients completed the questionnaire and on average reported a 'much better' situation. In conclusion, the construction of a continent catheterizable urinary conduit in adults is associated with a high complication and reoperation rate. Nevertheless, patients perceive improvement compared to before the construction of the stoma.
\end{abstract}

Keywords urinary diversion $\cdot$ adults $\cdot$ reoperations $\cdot$ complications

Ilse M. Groenendijk

i.groenendijk@erasmusmc.nl

1 afdeling Urologie, Erasmus Medisch Centrum, Rotterdam, Nederland

2 afdeling Urologie, Universitair Medisch Centrum Groningen, Rijksuniversiteit Groningen, Groningen, Nederland

\section{Introductie}

Veel patiënten met een neurogene of niet-neurogene blaasontledigingsstoornis zijn afhankelijk van zelfkatheterisatie of hebben een verblijfskatheter. Ondanks goede instructies, begeleiding en de juiste benodigdheden, hebben deze patiënten toch een verhoogde kans op urineweginfecties, pijn en bloedingen [1-3]. Bij rolstoelgebonden patiënten of patiënten met een beperkte handfunctie verloopt zelfkatheterisatie vaak moeizaam. De urineweginfec- 
ties, pijnlijke/moeizame katheterisaties of bloedingen hebben soms een substantiële invloed op de kwaliteit van leven. Als zelfkatheterisatie of een verblijfskatheter niet mogelijk is of de kwaliteit van leven te veel aantast, kan een continent katheteriseerbaar urostoma aangelegd worden [4]. De twee meest gebruikte technieken voor het aanleggen van een katheteriseerbaar stoma zijn de Mitrofanoff appendicovesicostomie en de Monti ileovesicostomie [5-7]. Deze worden al drie decennia lang bij zowel kinderen als volwassenen toegepast. Het aanleggen van een continent katheteriseerbaar urostoma bij kinderen is een effectieve en duurzame oplossing gebleken [8]. De literatuur over de uitkomst bij volwassenen is schaars en betreft vaak alleen neurogene patiënten [7, 9-11]. De beschreven cohorten zij klein en hebben een grote spreiding in de percentages complicaties en re-operaties.

Het doel van deze studie was om de langetermijnresultaten te beschrijven van het aanleggen van een continent katheteriseerbaar urostoma bij volwassenen met een neurogene of een niet-neurogene blaasontledigingsstoornis.

\section{Materiaal}

De medische dossiers van 41 patiënten die op volwassen leeftijd ( $>16$ jaar) een continent urostoma aangelegd hebben gekregen, werden retrospectief onderzocht. De ingrepen waren uitgevoerd tussen november 1998 en november 2016 in het Erasmus MC en het Universitair Medisch Centrum Groningen (UMCG) door drie verschillende urologen (JS, JH, RN). Zowel de Mitrofanoff- als de Montiprocedure was toegepast $[5,6]$ en het stoma was hetzij in de navel, hetzij in de rechteronderbuik geplaatst. Na de ingreep werd er een katheter achtergelaten in het stoma die drie tot zes weken later werd verwijderd. De patiënt kreeg zelfkatheterisatie aangeleerd en kwam iedere drie tot zes maanden voor controle. Als de blaasfunctie stabiel bleef en katheterisatie probleemloos verliep, werd het follow-upinterval verlengd tot een jaar.

$\mathrm{Na}$ toestemming te hebben verkregen van de Medisch Ethische Toetsings Commissie (METC), werd er een vragenlijst opgestuurd naar de patiënten die in december 2017 het stoma nog in gebruik hadden. Deze vragenlijst bestond uit vijf items. De eerste was de Patient Global Impression of Improvement (PGI-I), met als eerste vraag hoe de patiënt zijn situatie nu beoordeelde ten opzichte van vóór het aanleggen van het stoma. De meerkeuzeopties varieerde van 1 'heel veel beter' tot 7 'heel veel slechter'. De volgende items betroffen: 2) continentie van het stoma ('volledig droog'/"een beetje lekkage maar 1 pad is genoeg'/'lekkage waarvoor stoma zakje noodzakelijk'/'volledig incontinent'); 3) urethrale incontinentie (heeft $\mathrm{u}$ de afgelopen twee weken ongewild urine verloren via de plasbuis? 'ja'/'nee'); 4) problemen met katheterisatie? ('altijd gemakkelijk'/'meestal gemakkelijk', 'soms moeilijk of pijnlijk'/'altijd moeilijk of pijnlijk'); en 5) zou $\mathrm{u}$ deze ingreep aanraden aan iemand met een vergelijkbare medische situatie? 'ja'/'nee'.

Gegevens zoals geslacht, leeftijd, body mass index (BMI) tijdens de ingreep, aantal opnamedagen rond de ingreep, onderliggend lijden en de indicatie voor de ingreep werden geëxtraheerd uit de status van de patiënten. De primaire uitkomstmaten waren complicaties en re-operaties. Stenose van het stoma werd onderverdeeld in een oppervlakkige stenose (tot fascieniveau) en diepe stenose (tot aan blaasniveau) en werd als complicatie geregistreerd als de stenose niet verholpen kon worden met minimaal-invasieve therapie, zoals ACE-stoppers of nachtelijke katheters en een dilatatie, of als een re-operatie nodig was. Lekkage van urine uit het stoma of de urethra werd als complicatie geregistreerd als de patiënt de lekkage niet voldoende kon opvangen met incontinentiemateriaal en een heringreep overwoog. Pijn of problemen tijdens zelfkatheterisatie werden als complicaties geregistreerd als de patiënt hiervoor de SEH of polikliniek bezocht of opgenomen werd in het ziekenhuis. Urosepsis dan wel urineweginfectie werd als complicatie geregistreerd als de patiënt om deze reden werd opgenomen in het ziekenhuis. Aan het stoma gerelateerde re-operaties werden onderverdeeld in stomarevisie (oppervlakkig), conduitrevisie (met daarbij een herimplantatie van het kanaal in de blaas), conduitvervanging (van Mitrofanoff naar Monti of van Monti naar een nieuwe Monti), het sluiten van het stoma, het gebruik van Bulkamid of botox en een ileocystoplastiek. Het gebruik van Bulkamid of botox in de urethra en dilatatie van het stoma onder algehele anesthesie werden wel geregistreerd, maar niet als stomagerelateerde complicatie.

Voor statistische analyses is SPSS Statistics 24 gebruikt. Niet-normaal verdeelde data worden gepresenteerd als mediaan met interkwartielafstanden. De Shapiro-Wilk-test werd gebruikt om na te gaan of de data normaal verdeeld waren. Non-parametrische en Chi-kwadraattoetsen werden gebruikt om de risicofactoren (leeftijd en BMI) voor een re-operatie te analyseren. Een $p$-waarde $<0,05$ werd als statistisch significant beschouwd.

\section{Resultaten}

De kenmerken van de patiënten zijn weergeven in tab. 1 . De mediane follow-up bedroeg 52 maanden, met een interkwartiel afstand van 19-120 maanden. Het onderliggend lijden was neurogeen bij 26 patiënten (63\%), en niet-neurogeen bij 15 patiënten $(37 \%)$. Bij 24 patiënten waren gelijktijdig met het aanleggen van het stoma andere ingre- 
Tabel 1 Patiëntkarakteristieken

\begin{tabular}{|c|c|}
\hline patiënten & $n=41$ \\
\hline geslacht $(\%) \mathrm{man} /$ vrouw & $12(29) / 29$ \\
\hline leeftijd tijdens ingreep, mediaan (IQR) & $32(23-49)$ \\
\hline BMI, mediaan (IQR), 14 ontbreken & $25(22,6-31,4)$ \\
\hline follow-upduur in maanden, mediaan (IQR) & $52(19-120)$ \\
\hline blaascapaciteit preoperatief in ml, mediaan (IQR), 8 ontbreken & $400(250-500)$ \\
\hline opnamedagen na de ingreep (range), 1 mist & $10(6-14)$ \\
\hline \multicolumn{2}{|l|}{ onderliggend lijden } \\
\hline neurogeen blaaslijden $(\%)$ & $26(63)$ \\
\hline - meningomyelocele & $11(27)$ \\
\hline - dwarslaesie/cerebrale contusie & $7(17)$ \\
\hline - multiple sclerose/andere spierziekte & $3(7)$ \\
\hline - polyneuropathie & $2(5)$ \\
\hline - cerebrale parese & $2(5)$ \\
\hline - bekken trauma & $1(2)$ \\
\hline niet-neurogeen blaaslijden $(\%)$ & $15(37)$ \\
\hline - idiopathische urineretentie & $4(9)$ \\
\hline - ernstige urethrale stricturen & $3(7)$ \\
\hline - blaas-pijnsyndroom & $1(2)$ \\
\hline - Ehlers-Danlos syndroom & $1(2)$ \\
\hline - Prune-Belly syndroom & $1(2)$ \\
\hline - overige & $5(12)$ \\
\hline \multicolumn{2}{|l|}{ indicatie aanleggen katheteriseerbaar urostoma } \\
\hline neurogeen blaaslijden $(\%)$ & $26(63)$ \\
\hline - urethrale lekkage ondanks CIC & $7(17)$ \\
\hline - verslechterde handfunctie & $6(15)$ \\
\hline - IC met rolstoelgebondenheid & $4(10)$ \\
\hline - urethrale stricturen/fistels door CIC & $4(10)$ \\
\hline - pijn tijdens CIC & $2(5)$ \\
\hline - overige & $3(7)$ \\
\hline niet-neurogeen blaaslijden $(\%)$ & $15(37)$ \\
\hline - pijn tijdens CIC & $5(13)$ \\
\hline - verslechterde hand/schouder functie & $4(10)$ \\
\hline - urethrale stricturen & $3(7)$ \\
\hline - CIC met rolstoelgebondenheid & $1(3)$ \\
\hline - overige & $2(5)$ \\
\hline \multicolumn{2}{|l|}{ type ingreep (\%) } \\
\hline Mitrofanoff & $24(59)$ \\
\hline Monti-buis & $17(41)$ \\
\hline
\end{tabular}

$I Q R$ interkwartiel afstand, $C I C$ zelfkatheterisatie

pen uitgevoerd; het vaakst een ileocystoplastiek $(n=16)$. In 6 gevallen betrof dat blaashalschirurgie en blaashalsslings. Twee patiënten ontvingen peroperatief botoxinjecties. Bij 35 patiënten $(85 \%)$ werd het stoma in de navel geplaatst; bij $6(15 \%)$ in de rechteronderbuik.

\section{Patiënten met neurogeen blaaslijden $(n=26)$}

Zie voor het onderliggend lijden en indicaties voor het aanleggen van het urostoma tab. 1. De patiënt met bekken- trauma had geen blaasactiviteit tijdens urodynamisch onderzoek.

\section{Patiënten met niet-neurogeen blaaslijden $(n=15)$}

Zie voor het onderliggend lijden en indicaties voor het aanleggen van het urostoma tab. 1. Eén patiënt vertoonde ernstige dysfunctional voiding met residuen en progressieve nierfunctieverslechtering; één patiënt had een conversiestoornis. Drie patiënten hadden een idiopathische hypocontractiele blaas. 
Tabel 2 Complicaties en re-operaties bij patiënten met neurogeen blaaslijden. Een oppervlakkige stenose is een stenose tot aan fascieniveau, een diepe stenose is een stenose tot aan blaasniveau

\begin{tabular}{|c|c|c|c|c|c|c|c|}
\hline $\begin{array}{l}\mathrm{Pt} . \\
\mathrm{nr}\end{array}$ & 1e complicatie & $\begin{array}{l}\text { mnd. tot 1e } \\
\text { complicatie }\end{array}$ & 2e complicatie & $\begin{array}{l}\text { mnd. tot } 2 \mathrm{e} \\
\text { complicatie }\end{array}$ & 3e complicatie & $\begin{array}{l}\text { mnd. tot } 3 \mathrm{e} \\
\text { complicatie }\end{array}$ & tot. FU \\
\hline 1 & $\begin{array}{l}\text { diepe stenose } \rightarrow \text { conduit } \\
\text { vervangen }\end{array}$ & 3 & - & - & - & - & 99 \\
\hline 2 & urosepsis & 0 & urosepsis & 3 & $\begin{array}{l}\text { stomale UI } \rightarrow \text { sluiten } \\
\text { stoma }\end{array}$ & 3 & 3 \\
\hline 3 & stomale UI & 28 & $\begin{array}{l}\dagger \text { (niet gerelateerd } \\
\text { aan urostoma) }\end{array}$ & - & - & - & $\mathrm{nb}$ \\
\hline 6 & oppervlakkige stenose & 12 & - & - & - & - & 54 \\
\hline 9 & $\begin{array}{l}\text { diepe stenose } \rightarrow \text { conduit } \\
\text { vervangen }\end{array}$ & 2 & $\begin{array}{l}\text { stomale UI } \rightarrow \text { per- } \\
\text { manent katheter in } \\
\text { stoma }\end{array}$ & 8 & - & - & 8 \\
\hline 10 & $\begin{array}{l}\text { oppervlakkige ste- } \\
\text { nose } \rightarrow \text { stoma sluiten }\end{array}$ & 8 & - & - & - & - & 38 \\
\hline 11 & - & - & - & - & - & - & 35 \\
\hline 13 & ernstige stomale pijn & 20 & - & - & - & - & 33 \\
\hline 15 & $\begin{array}{l}\text { diepe stenose } \rightarrow \text { conduit } \\
\text { vervangen }\end{array}$ & 11 & - & - & - & - & 27 \\
\hline 16 & $\begin{array}{l}\text { oppervlakkige ste- } \\
\text { nose } \rightarrow \text { stomarevisie }\end{array}$ & 25 & - & - & - & - & 50 \\
\hline 21 & - & - & - & - & - & - & 231 \\
\hline 22 & $\begin{array}{l}\text { oppervlakkige ste- } \\
\text { nose } \rightarrow \text { conduit ver- } \\
\text { vangen }\end{array}$ & 3 & $\begin{array}{l}\text { stomale UI } \rightarrow \text { con- } \\
\text { duitrevisie }\end{array}$ & 9 & $\begin{array}{l}\text { oppervlakkige ste- } \\
\text { nose } \rightarrow \text { dilatatie }\end{array}$ & 41 & 227 \\
\hline 23 & stomale UI $\rightarrow$ B-A & 47 & - & - & - & - & 183 \\
\hline 25 & oppervlakkige stenose & 2 & urethrale UI $\rightarrow$ B-A & 10 & $\begin{array}{l}\text { oppervlakkige ste- } \\
\text { nose } \rightarrow \text { conduitrevisie }\end{array}$ & 27 & 71 \\
\hline 26 & urethrale UI $\rightarrow$ B-A & 78 & $\begin{array}{l}\dagger \text { (niet gerelateerd } \\
\text { aan urostoma) }\end{array}$ & 96 & - & - & 90 \\
\hline 28 & $\begin{array}{l}\text { oppervlakkige ste- } \\
\text { nose } \rightarrow \text { stomarevisie }\end{array}$ & 37 & - & - & - & - & 67 \\
\hline 29 & $\begin{array}{l}\text { oppervlakkige ste- } \\
\text { nose } \rightarrow \text { dilatatie }\end{array}$ & - & - & - & - & - & 15 \\
\hline 31 & $\begin{array}{l}\text { oppervlakkige ste- } \\
\text { nose } \rightarrow \text { stomarevisie }\end{array}$ & 0 & $\begin{array}{l}\text { diepe stenose } \rightarrow \\
\text { conduit vervangen }\end{array}$ & 2 & - & - & 123 \\
\hline 33 & - & - & - & - & - & - & 219 \\
\hline 34 & $\begin{array}{l}\text { oppervlakkige ste- } \\
\text { nose } \rightarrow \text { stomarevisie }\end{array}$ & 4 & - & - & - & - & 120 \\
\hline 35 & - & - & - & - & - & - & 46 \\
\hline 36 & $\begin{array}{l}\text { oppervlakkige ste- } \\
\text { nose } \rightarrow \text { stomarevisie }\end{array}$ & 11 & urethrale UI $\rightarrow$ B-A & 22 & - & - & 159 \\
\hline 38 & - & - & - & - & - & - & 175 \\
\hline 39 & - & - & - & - & - & - & 217 \\
\hline 40 & - & - & - & - & - & - & 164 \\
\hline 41 & $\begin{array}{l}\text { oppervlakkige ste- } \\
\text { nose } \rightarrow \text { stomarevisie }\end{array}$ & 27 & $\begin{array}{l}\text { oppervlakkige ste- } \\
\text { nose } \rightarrow \text { stomarevisie }\end{array}$ & 53 & $\begin{array}{l}\text { oppervlakkige ste- } \\
\text { nose } \rightarrow \text { stomarevisie }\end{array}$ & 111 & 155 \\
\hline
\end{tabular}

$B$ - $A$ bulking agent, $n b$ niet bekend, $m n d$. maanden, Tot. $F U$ totale follow-up, $U I$ urine-incontinentie, $\dagger$ overleden

\section{Complicaties en re-operaties}

In totaal ondergingen 20 patiënten $(48,8 \%)$ na het aanleggen van het urostoma een re-operatie na gemiddeld 10,5 maanden (mediaan, interkwartielafstand 4,5-30,8). Er was geen verschil in percentage complicaties tussen beide cen- tra. Van alle geregistreerde complicaties was de oppervlakkige stenose de meest voorkomende complicatie (20 keer) gevolgd door stomale incontinentie (10 keer). Stenose op diep niveau werd vier keer geregistreerd en stomale pijn drie keer. Stomarevisie was de meest voorkomende re-operatie (12 keer), gevolgd door conduitvervanging (6 keer). De 
Tabel 3 Complicaties en re-operaties bij patiënten met niet-neurogeen blaaslijden. Een oppervlakkige stenose is een stenose tot aan fascieniveau; diepe stenose is een stenose tot aan blaasniveau

\begin{tabular}{|c|c|c|c|c|c|c|c|}
\hline $\begin{array}{l}\mathrm{Pt} . \\
\mathrm{nr}\end{array}$ & 1e complicatie & $\begin{array}{l}\text { mnd. tot 1e } \\
\text { complicatie }\end{array}$ & 2e complicatie & $\begin{array}{l}\text { mnd. tot } 2 \mathrm{e} \\
\text { complicatie }\end{array}$ & 3e complicatie & $\begin{array}{l}\text { mnd. tot } 3 \mathrm{e} \\
\text { complicatie }\end{array}$ & $\begin{array}{l}\text { tot. FU } \\
\text { in mnd. }\end{array}$ \\
\hline 4 & ernstige stomale pijn & 2 & $\begin{array}{l}\dagger(\text { niet gerelateerd aan } \\
\text { urostoma) }\end{array}$ & - & - & - & 64 \\
\hline 5 & stomale UI & 28 & - & - & - & - & 71 \\
\hline 7 & diepe stenose & 33 & - & - & - & - & 46 \\
\hline 8 & ernstige stomale pijn & 1 & $\begin{array}{l}\text { stomale UI } \rightarrow \text { con- } \\
\text { duitrevisie }\end{array}$ & 2 & $\begin{array}{l}\text { ernstige stomale } \\
\text { pijn } \rightarrow \text { stoma sluiten }\end{array}$ & 14 & 14 \\
\hline 12 & $\begin{array}{l}\text { stomale UI } \rightarrow \text { augmen- } \\
\text { tatie }\end{array}$ & 5 & - & - & - & - & 33 \\
\hline 14 & $\begin{array}{l}\text { oppervlakkige ste- } \\
\text { nose } \rightarrow \text { stomarevisie }\end{array}$ & 18 & - & - & - & - & 32 \\
\hline 17 & - & - & - & - & - & - & 22 \\
\hline 18 & $\begin{array}{l}\text { stomale UI } \rightarrow \text { stomare- } \\
\text { visie }\end{array}$ & 6 & $\begin{array}{l}\text { oppervlakkige ste- } \\
\text { nose } \rightarrow \text { stoma sluiten }\end{array}$ & 7 & - & - & 12 \\
\hline 19 & - & - & - & - & - & - & 17 \\
\hline 20 & $\begin{array}{l}\text { stomale UI } \rightarrow \text { perma- } \\
\text { nent katheter in stoma }\end{array}$ & 3 & - & - & - & - & 3 \\
\hline 24 & - & - & - & - & - & - & 47 \\
\hline 27 & $\begin{array}{l}\text { oppervlakkige ste- } \\
\text { nose } \rightarrow \text { stomarevisie }\end{array}$ & 35 & $\begin{array}{l}\text { oppervlakkige ste- } \\
\text { nose } \rightarrow \text { conduitrevisie }\end{array}$ & 48 & urosepsis & 73 & 89 \\
\hline 30 & - & - & - & - & - & - & 72 \\
\hline 32 & - & - & - & - & - & - & 100 \\
\hline 37 & $\begin{array}{l}\text { oppervlakkige ste- } \\
\text { nose } \rightarrow \text { stomarevisie }\end{array}$ & 64 & - & - & - & - & 124 \\
\hline
\end{tabular}

mnd. maanden, Tot. FU totale follow-up, UI urine-incontinentie, $\dagger$ overleden

complicaties bij patiënten met neurogeen blaaslijden zijn gedetailleerd weergegeven in tab. 2 .

De complicaties en re-operaties bij patiënten met nietneurogeen blaaslijden zijn weergeven in tab. 3. Bij 19 (73\%) van de 29 patiënten met een neurogene blaas werden een of meer complicaties geregistreerd. Bij $10(67 \%)$ van de 15 niet-neurogene patiënten werd een complicatie geregistreerd. Dit verschil was niet significant $\left(X^{2}\right.$-toets; $p=0,189$ ).

\section{De kans op re-operatie}

Bij de analyse van de factoren die mogelijk een invloed hadden op het re-operatierisico werd uitgegaan van de mediane leeftijd van 32 jaar. Patiënten $\geq 32$ jaar die een stoma aangelegd kregen hadden een significant hogere kans op reoperatie dan patiënten $<32$ jaar die een stoma kregen $\left(X^{2}-\right.$ toets; $p=0,043$ ). Ook werd geanalyseerd of een BMI boven of onder de mediaan (25) een significant verschil maakte voor de kans op re-operatie. Dit verschil was statistisch niet significant $(p=0,431)$. Van 14 patiënten was informatie over de BMI ten tijde van de ingreep niet beschikbaar.

\section{Vragenlijst}

De vragenlijst werd verstuurd naar de 32 (van de 41) patiënten die ten tijde van dit onderzoek hun stoma nog in gebruik hadden. Bij vier patiënten was het stoma chirurgisch gesloten; twee droegen permanent een katheter in het stoma, en drie patiënten waren inmiddels overleden. De responsratio was 24/32 (75\%), vijf mannen, 19 vrouwen. De gemiddelde score op de PGI-I vraag was 2 ('veel beter') en met uitzondering van twee patiënten zou iedereen de operatie aanraden aan iemand in een vergelijkbare medische situatie. Van de 10 patiënten die urinelekkage uit het stoma hadden gemeld, maar genoeg hadden aan 1 pad om het op te vangen, hadden er vier een ileocystoplastiek ondergaan tijdens het aanleggen van het stoma. Van de negen patiënten met urethrale incontinentie hadden er vijf een ileocystoplastiek ondergaan, allen vrouw. Zie tab. 4 voor alle resultaten van de vragenlijst.

\section{Discussie}

Van de 41 patiënten die een continent katheteriseerbare urostoma kregen, bleven er 12 volledig complicatievrij. De overige 29 kregen minstens één keer te maken met onder 
Tabel 4 Resultaten van de Patient Global Impression of Improvement (PGI-I)

\begin{tabular}{|c|c|}
\hline Vragen & $n=24$ \\
\hline \multicolumn{2}{|l|}{$P G I-I$} \\
\hline 1. Heel veel beter & 9 \\
\hline 2. Veel beter & 8 \\
\hline 3. Beetje beter & 3 \\
\hline 4. Geen verandering & 1 \\
\hline 5. Beetje slechter & 2 \\
\hline 6. Veel slechter & 1 \\
\hline 7. Heel veel slechter & 0 \\
\hline \multicolumn{2}{|l|}{ Continentiestoma } \\
\hline Volledig droog & 11 \\
\hline Lekt soms, pad/verband voldoende & 10 \\
\hline Incontinent/katheter/overig & $1 / 1 / 1$ \\
\hline \multicolumn{2}{|l|}{ Continentie-urethra } \\
\hline $\mathrm{Ja}$ & 15 \\
\hline Nee & 9 \\
\hline \multicolumn{2}{|l|}{ Katheterisatiestoma $a^{\mathrm{a}}$} \\
\hline Altijd gemakkelijk en pijnloos & 9 \\
\hline Meestal gemakkelijk, soms moeizaan/pijn & 10 \\
\hline Meestal moeizaam of pijnlijk & 2 \\
\hline Altijd moeizaam of pijnlijk & 2 \\
\hline \multicolumn{2}{|l|}{ Zou je deze ingreep adviseren aan een ander? } \\
\hline $\mathrm{Ja}$ & 22 \\
\hline Nee & 2 \\
\hline
\end{tabular}

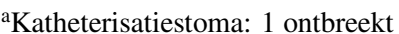

andere stenose, incontinentie of pijn, waarvoor 20 patiënten minimaal één re-operatie ondergingen. Toch beoordeelde men gemiddeld de situatie als veel beter dan vóór de ingreep en zouden de meesten deze ingreep bij anderen aanbevelen. Goede counseling en shared decision making is alleen mogelijk als zowel de uroloog als de patiënt op de hoogte is van de kans op complicaties en van de verwachte uitkomsten.

Het aanleggen van een continent katheteriseerbaar urostoma bij volwassenen is een toepasbare therapie. Zeker omdat er geen andere opties zijn voor patiënten voor wie zelfkatheterisatie of de verblijfskatheter een te grote negatieve impact heeft op de kwaliteit van leven. Een alternatief zou een incontinent urostoma (Bricker-deviatie) kunnen zijn. Deze stelt echter de hoge urinewegen bloot aan risico's en de meeste patiënten prefereren een continent stoma [12].

Het aantal re-operaties bij deze groep patiënten $(48,8 \%)$ is vergelijkbaar met het aantal re-operaties dat is beschreven in de schaarse literatuur over dit onderwerp (tab. 5; [11, 13-17]). Eerder hebben verschillende onderzoekers geprobeerd risicofactoren voor complicaties te identificeren bij volwassenen bij wie een continent katheteriseerbaar stoma werd aangelegd. De Ganck et al. beschrijven 52 patiënten bij wie multipele regressieanalyse geen significant verhoogd risico op complicaties liet zien voor de oudere patiënten versus jongere patiënten [17]. Een studie van Sahadevan et al. bij een groep van 29 patiënten beschrijft een significant verhoogd risico op complicaties bij een leeftijd hoger dan 50 jaar [14]. Terugkerende punten van discussie zijn het kleine aantal patiënten en de heterogeniteit van de onderzochte cohorten. Dit zijn kenmerken die invloed hebben op de uit te voeren statistiek en die de identificatie van risicofactoren erg lastig maken. Wij vonden een significant verhoogd risico voor een re-operatie bij patiënten ouder dan 32 jaar in vergelijking met jongere patiënten. Deze resultaten moeten met enige terughoudendheid geïnterpreteerd worden, aangezien de follow-upduur bias kan veroorzaken. Een verhoogd BMI vormde in onze studie geen risicofactor voor een complicatie of een re-operatie, maar dit zou kunnen liggen aan het relatief kleine aantal geïncludeerde patiënten. Bovendien is de BMI bij patiënten met een spina bifida of een dwarslaesie niet altijd representatief voor de hoeveelheid buikvet, aangezien het BMI geen rekening houdt met een verminderde spiermassa in de benen. Een verhoogd BMI is in studies die andere soorten stoma's onderzochten (o.a. colorectale stoma's) wel als risicofactor voor stomagerelateerde problemen aangetoond [18]. Deze informatie kan de uroloog en de patiënt helpen bij het maken van een weloverwogen beslissing om een continent katheteriseerbaar urostoma wel of niet aan te leggen. Aan het eind van de follow-upperiode hadden 9 van de 41 patiënten in onze studie het stoma niet meer in gebruik. Drie van deze patiënten waren overleden, maar niet in directe relatie tot het stoma. Wegens complicaties zoals pijn bij zelfkatheterisatie en lekkage was bij vier patiënten het stoma chirurgisch gesloten, en twee droegen permanent een katheter in het stoma. Hopelijk kan er in de toekomst, aan de hand van de identificatie van risicofactoren, beter worden bepaald of een patiënt wel of niet in aanmerking komt voor een continent katheteriseerbaar urostoma.

Behalve de patiëntgerelateerde risicofactoren spelen ook externe factoren een belangrijke rol. Een goed gespecialiseerd behandelteam kan met goede instructies aan de patient, het verstrekken van het juiste materiaal en het bieden van optimale begeleiding de kans op traumatische katheterisaties kleiner maken en daarmee de kans op complicaties verkleinen.

Een mogelijk beperking van deze studie is dat de vragenlijst niet is verstuurd naar de patiënten die het stoma niet meer gebruikten. Mogelijk is hierdoor bias van de resultaten opgetreden. Ook werd aan de patiënten gevraagd om de huidige situatie te vergelijken met de situatie vóór de ingreep, maar dat was soms lang geleden. Negen patiënten gaven aan urethrale lekkage te hebben. Vijf van de negen (allen vrouw) ondergingen een ileocystoplastiek. We kunnen met deze vragenlijst niet differentiëren tussen urineverlies wegens een te lage blaascapaciteit of een pre- 
Tabel 5 Publicaties over katheteriseerbare urostoma's

\begin{tabular}{lllllccc}
\hline auteur & jaar & N/NN & follow-up (IQR/bereik) & leeftijd in jaren (SD) & continentie & stenose & re-operatie \\
\hline huidige studie & 2019 & $26 / 15$ & 52 mnd. (IQR 19-120) & $32(23-49)$ & $88 \%$ & $46 \%$ & $49 \%$ \\
Perrouin-Verbe et al. [11] & 2016 & $29 / 0$ & 66 mnd. (IQR 50-80) & $35(26-46)$ & $100 \%$ & $6 \%$ & $24 \%$ \\
Rey et al. [15] & 2013 & $11 / 4$ & 22 mnd. (bereik 9-33) & $32(22-65)$ & - & - & $20 \%$ \\
van der Aa et al. [13] & 2009 & $12 / 23$ & 62 mnd. (bereik 6-117) & $44(21-80)$ & $75 \%$ & $29 \%$ & $54 \%$ \\
Sahadevan et al. [14] & 2008 & $7 / 22$ & 10,5 jaar (bereik 0,4-16) & $48(18-79)$ & $89 \%$ & $57 \%$ & $49 \%$ \\
Touma et al. [9] & 2007 & $12 / 0$ & 2,8 jaar (bereik 0,25-5,8) & $27(14-50)$ & - & - & - \\
Karsenty et al. [16] & 2007 & $12 / 0$ & 44 mnd. (bereik 20-56) & $42(18-63)$ & $100 \%$ & - & $17 \%$ \\
\hline
\end{tabular}

$N$ neurogeen blaaslijden, $N N$ niet-neurogeen blaaslijden, $S D$ standaarddeviatie, $I Q R$ interkwartielafstand

existente stressincontinentie. De blaascapaciteit en blaasdruk werden preoperatief beoordeeld en aan de hand daarvan werd besloten of er ook een ileocystoplastiek moest worden verricht.

\section{Conclusie}

Deze studie laat zien dat de aanleg van een continent katheteriseerbaar urostoma bij volwassenen gepaard kan gaan met een hoog percentage re-operaties, zonder dat daar duidelijke risicofactoren voor aanwezig zijn. De uroloog moet, samen met de patiënt, de kans op complicaties afwegen tegen de verbetering in kwaliteit van leven, ook in het licht van het ontbreken van andere opties. Prospectieve studies met grotere cohorten zijn nodig om de risicofactoren voor complicaties duidelijker te maken.

Open Access This article is distributed under the terms of the Creative Commons Attribution 4.0 International License (http:// creativecommons.org/licenses/by/4.0/), which permits unrestricted use, distribution, and reproduction in any medium, provided you give appropriate credit to the original author(s) and the source, provide a link to the Creative Commons license, and indicate if changes were made.

\section{Literatuur}

1. Wyndaele JJ. Complications of intermittent catheterization: their prevention and treatment. Spinal Cord. 2002;40(10):536-41.

2. Igawa Y, Wyndaele JJ, Nishizawa O. Catheterization: possible complications and their prevention and treatment. Int $\mathrm{J}$ Urol. 2008;15(6):481-5.

3. Di Benedetto P. Clean intermittent self-catheterization in neurourology. Eur J Phys Rehabil Med. 2011;47(4):651-9.

4. Groen J, Pannek J, Castro Diaz D, et al. Summary of European Association of Urology (EAU) guidelines on neuro-urology. Eur Urol. 2016;69(2):324-33.

5. Monti PR, Lara RC, Dutra MA, et al. New techniques for construction of efferent conduits based on the Mitrofanoff principle. Urology. 1997;49(1):112-5.

6. Mitrofanoff P. Trans-appendicular continent cystostomy in the management of the neurogenic bladder (Cystostomie continente transappendiculaire dans le traitement des vessies neurologiques). Chir Pediatr. 1980;21(4):297-305.
7. Ardelt PU, Woodhouse CR, Riedmiller H, et al. The efferent segment in continent cutaneous urinary diversion: a comprehensive review of the literature. BJU Int. 2012;109(2):288-97.

8. Reuvers $\mathrm{SH}$, Hoek J van den, Blok BF, et al. 20 years experience with appendicovesicostomy in paediatric patients: Complications and their re-interventions. Neurourol Urodyn. 2017;36(5):1325-9.

9. Touma NJ, Horovitz D, Shetty A, et al. Outcomes and quality of life of adults undergoing continent catheterizable vesicostomy for neurogenic bladder. Urology. 2007;70(3):454-8.

10. Phe V, Boissier R, Blok BFM, et al. Continent catheterizable tubes/stomas in adult neuro-urological patients: A systematic review. Neurourol Urodyn. 2017;36(7):1711-22.

11. Perrouin-Verbe MA, Chartier-Kastler E, Even A, et al. Long-term complications of continent cutaneous urinary diversion in adult spinal cord injured patients. Neurourol Urodyn. 2016;35(8):1046-50.

12. Guillot-Tantay C, Chartier-Kastler E, Perrouin-Verbe MA, et al. Complications of non-continent cutaneous urinary diversion in adults with spinal cord injury: a retrospective study. Spinal Cord. 2018;56(9):856-62.

13. Van der Aa F, Joniau S, De Baets K, et al. Continent catheterizable vesicostomy in an adult population: success at high costs. Neurourol Urodyn. 2009;28(6):487-91.

14. Sahadevan K, Pickard RS, Neal DE, et al. Is continent diversion using the Mitrofanoff principle a viable long-term option for adults requiring bladder replacement? BJU Int. 2008;102(2):236-40.

15. Rey D, Helou E, Oderda M, et al. Laparoscopic and robot-assisted continent urinary diversions (Mitrofanoff and Yang-Monti conduits) in a consecutive series of 15 adult patients: the Saint Augustin technique. BJU Int. 2013;112(7):953-8.

16. Karsenty G, Chartier-Kastler E, Mozer P, et al. A novel technique to achieve cutaneous continent urinary diversion in spinal cord-injured patients unable to catheterize through native urethra. Spinal Cord. 2008;46(4):305-10.

17. De Ganck J, Everaert K, Van Laecke E, et al. A high easy-totreat complication rate is the price for a continent stoma. BJU Int. 2002;90(3):240-3.

18. Parmar KL, Zammit M, Smith A, et al. A prospective audit of early stoma complications in colorectal cancer treatment throughout the Greater Manchester and Cheshire colorectal cancer network. Colorectal Dis. 2011;13(8):935-8.

Ilse M. Groenendijk arts-assistent, arts-onderzoeker urologie

Jeroen R. Scheepe uroloog

Bertil F.M. Blok uroloog

Rien J.M. Nijman uroloog

Joop van den Hoek uroloog 